\title{
Insulin in the ventral tegmental area reduces cocaine-evoked dopamine in the nucleus accumbens in vivo
}

\author{
Lindsay Naef, ${ }^{1}$ Lauren Seabrook, ${ }^{1}$ (D) Jeff Hsiao, ${ }^{2}$ Calvin Li ${ }^{2}$ and Stephanie L. Borgland ${ }^{1}$ \\ ${ }^{1}$ Department of Physiology \& Pharmacology, Cumming School of Medicine, Hotchkiss Brain Institute, University of Calgary, \\ Calgary, Alberta, T2N 4N1, Canada \\ ${ }^{2}$ Department of Anesthesiology, Pharmacology and Therapeutics, University of British Columbia, Vancouver, British Columbia, \\ Canada
}

Keywords: cocaine, dopamine, fast scan cyclic voltammetry, insulin, NAc, VTA

\begin{abstract}
Mesolimbic dopamine circuits, implicated in incentive motivation, are sensitive to changes in metabolic state such as weight loss and diet-induced obesity. These neurons are important targets for metabolic hormones such as leptin, glucagon-like peptide-1, ghrelin and insulin. Insulin receptors are located on dopamine neurons in the ventral tegmental area (VTA) and we have previously demonstrated that insulin induces long-term depression of excitatory synapses onto VTA dopamine neurons. While insulin can decrease dopamine concentration in somatodendritic regions, it can increase dopamine in striatal slices. Whether insulin directly targets the VTA to alter dopamine release in projection areas, such as the nucleus accumbens (NAc), remains unknown. The main goal of the present experiments was to examine NAc dopamine concentration following VTA administration of insulin. Using in vivo FSCV to detect rapid fluctuations in dopamine concentration, we showed that intra-VTA insulin via action at insulin receptors reduced pedunculopontine nucleus-evoked dopamine release in the NAc. Furthermore, intra-VTA insulin reduced cocaine-potentiated NAc dopamine. Finally, intra-VTA or intranasal insulin decreased locomotor responses to cocaine, an effect blocked by an intra-VTA administered insulin receptor antagonist. Together, these data demonstrate that mesolimbic dopaminergic projections are important targets of the metabolic hormone, insulin.
\end{abstract}

\section{Introduction}

The ventral tegmental area (VTA) and its mesolimbic dopaminergic projections relay information about environmental cues that predict motivationally relevant outcomes and are sensitive to changes in metabolic state (Naef et al., 2015; Fortin \& Roitman, 2017a; Sandhu et al., 2018). Feeding increases dopamine release and dopamine turnover in the nucleus accumbens (NAc) and the magnitude is greater in hungry compared to sated states (Wilson et al., 1995; Bassareo \& Di Chiara, 1999). Indeed, VTA dopamine neurons express many receptors that respond to peripheral peptides that signal metabolic status (Liu \& Borgland, 2015). Insulin (Figlewicz et al., 2003; Liu et al., 2013), leptin (Figlewicz et al., 2003; Leshan et al., 2010), glucagon-like peptide-1(GLP-1) (Göke et al., 1995; Merchenthaler et al., 1999) and ghrelin receptors (Abizaid et al., 2006) are located on tyrosine hydroxylase (TH)-positive neurons in

Correspondence: Stephanie Borgland, as above

E-mail: s.borgland@ucalgary.ca

Received 22 June 2018, revised 8 November 2018, accepted 13 November 2018

Edited by Prof. Paul Bolam. Reviewed by David Belim and Mark Ungless.

All peer review communications can be found with the online version of the article. the VTA. The administration of leptin in the VTA decreases dopamine in the NAc (Fulton et al., 2006), possibly via a decrease in firing (Hommel et al., 2006) or excitatory synaptic transmission (Thompson \& Borgland, 2013) onto dopamine neurons. Similarly, a GLP-1 receptor agonist, extendin-4, decreases excitatory synaptic transmission onto NAc-projecting dopamine neurons (Wang et al., 2015) and decreases dopamine release in the NAc (Fortin \& Roitman, 2017b). Both intra-VTA leptin or GLP-1 agonists decrease food intake (Fulton et al., 2006; Hommel et al., 2006; Alhadeff et al., 2012; Wang et al., 2015).

Insulin in the VTA can also reduce palatable food consumption in sated animals (Bruijnzeel et al., 2011; Mebel et al., 2012), sucrose self-administration stimulated by $\mu$-opioid receptor activation (Figlewicz et al., 2008), food anticipatory behavior (Labouèbe et al., 2013) and conditioned place preference for food (Labouèbe et al., 2013). Furthermore, insulin inhibits excitatory synaptic transmission onto VTA dopamine neurons via an endocannabinoid-mediated suppression of excitatory inputs (Labouèbe et al., 2013). However, insulin also increases the firing frequency of VTA dopamine neurons and deletion of insulin receptors on dopamine neurons decreases $\mathrm{TH}$ expression (the rate-limiting step in the synthesis of dopamine) without altering VTA or NAc dopamine concentration (Könner et al., 2011). 
Insulin has opposing effects on dopamine in somatodendrites compared to terminal release. Application of insulin to striatal slices increases terminal dopamine concentration via action at insulin receptors on cholinergic interneurons to promote dopamine release (Stouffer et al., 2015). In the VTA, insulin reduces somatodendritic dopamine concentration by upregulating dopamine transporters (Mebel et al., 2012), an effect that has also been demonstrated in the striatum (Patterson et al., 1998; Williams et al., 2007; Speed et al., 2011). However, it is unknown whether insulin directly targets the VTA to alter evoked dopamine release in the NAc. Therefore, the goal of the present experiments was to examine whether intra-VTA insulin alters pedunculopontine nucleus (PPTg)-evoked NAc dopamine release using in vivo fast scan cyclic voltammetry (FSCV) in anesthetized rats. In contrast to stimulation of the medial forebrain bundle or the VTA, which directly evokes NAc dopamine release, stimulation of the PPTg induces burst firing of dopamine neurons (Floresco et al., 2003; Zweifel et al., 2009) to evoke NAc dopamine release. We also tested if intra-VTA insulin can influence cocaine-potentiated NAc dopamine or locomotor activity.

\section{Materials and methods}

\section{Animals}

All experiments were performed in accordance with the ethical guidelines established by the Canadian Council for Animal Care and experimental protocols were approved by the animal care committees of the University of British Columbia and the University of Calgary. Adult male $(275-300$ g) Sprague Dawley rats were obtained from Charles River Laboratories (Quebec). Male and female P60 DAT ${ }^{\text {IRES }}{ }^{2}$ : TdTomato mice (Jax stock $006660 \times$ 007914 (Ai140); C57BL6 background) bred in house or C57BL6 (Charles River, HQ Canada) were used for intranasal insulin experiments. Rats and mice were maintained on a $12 \mathrm{~h}$ light/dark cycle and given ad libitum access to laboratory chow and water. All experiments were conducted during the animal's light phase.

\section{In vivo fast scan cyclic voltammetry}

Rapid fluctuations in evoked extracellular dopamine concentrations were measured with FSCV in anesthetized (urethane, $2 \mathrm{mg} / \mathrm{kg}$, Fig. 1a) rats. To directly target the VTA, a guide cannula (22 gauge, Plastics One) was positioned above the VTA (relative to bregma: $-5.6 \mathrm{~mm}$ posterior, $0.5 \mathrm{~mm}$ lateral, $-7.0 \mathrm{~mm}$ ventral) and secured to the skull with stainless steel screws and dental cement. A chlorinated-silver wire $(\mathrm{Ag} / \mathrm{AgCl})$ reference electrode was implanted in the contralateral cortex. A micromanipulator containing the recording electrode (carbon fiber electrode pulled through a glass pipette cut to a final exposed length of 150-180 $\mu \mathrm{m}, 7 \mu \mathrm{m}$ diameter, Goodfellow, Coraopolis, PA, USA) was inserted into the right NAc core (NAc, relative to bregma: $1.3 \mathrm{~mm}$ anterior, $1.3 \mathrm{~mm}$ lateral, $-7.0 \mathrm{~mm}$ ventral). The recording electrode and reference electrode were connected to a headstage and the potential of the recording electrode was scanned from -0.4 to $+1.3 \mathrm{~V}$ (vs. $\mathrm{Ag} / \mathrm{AgCl}$ ) and back $(400 \mathrm{~V} / \mathrm{s} ; 10 \mathrm{~Hz})$ to induce the oxidation and reduction of catecholamines at the tip of the recording electrode (depicted in Fig. 1b). A bipolar stimulating electrode (Plastics One) was gradually lowered into the pedunculopontine tegmental nucleus (PPTg,

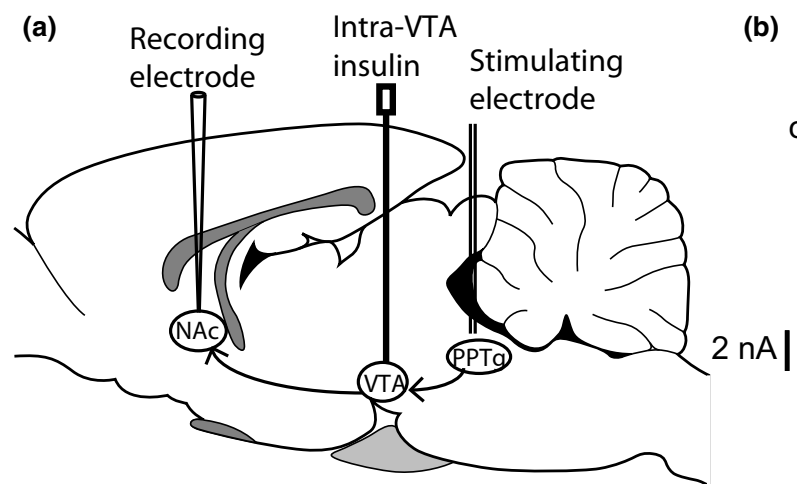

(b)

(d)

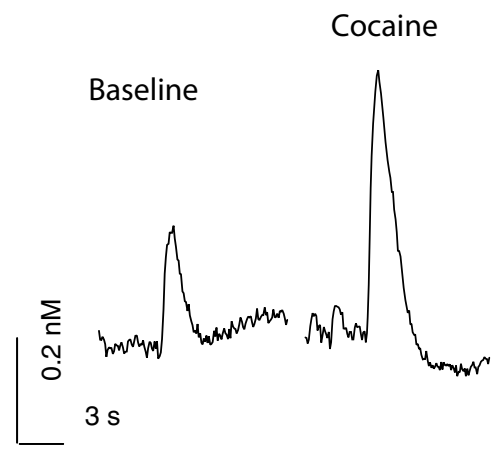

(e)
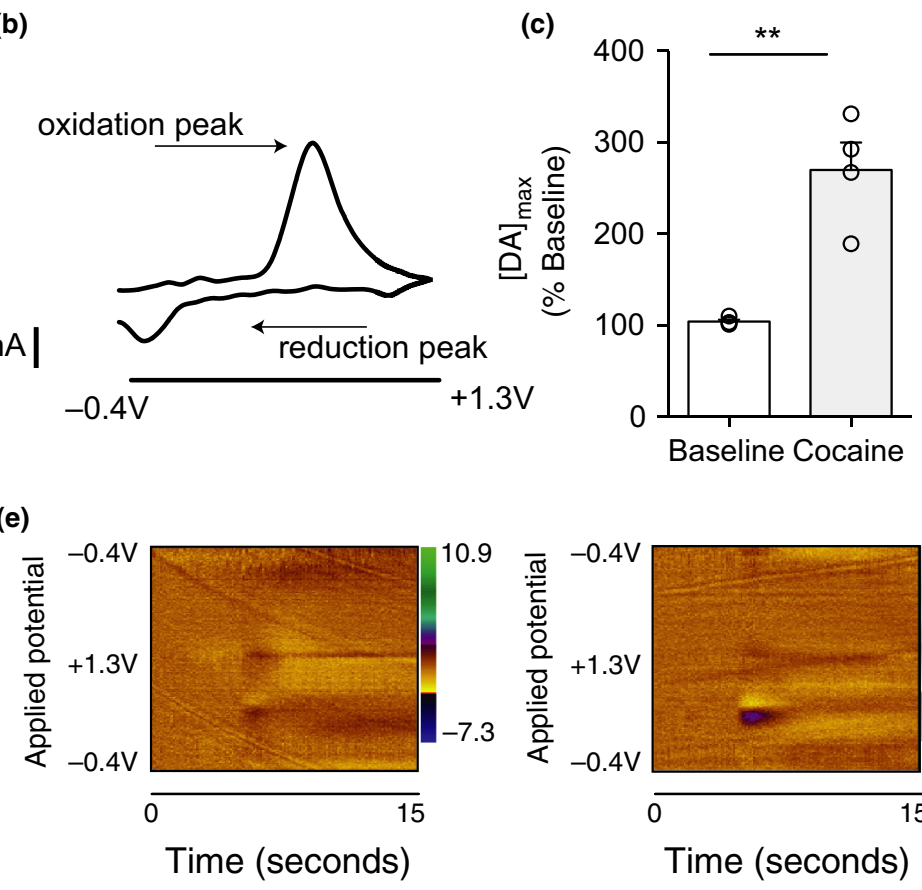

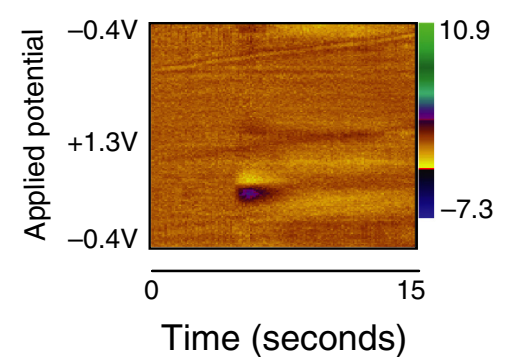

FIG. 1. PPTg stimulation evokes dopamine release in the nucleus accumbens. a. Schematic of a rat brain and the placement of the recording electrode in the NAc, the stimulating electrode in the PPTg and cannula located above the VTA for infusions of insulin during FSCV. b. The potential of the recording electrode was scanned from -0.4 to $+1.3 \mathrm{~V}$ (vs. $\mathrm{Ag} / \mathrm{AgCl})$ and back $(400 \mathrm{~V} / \mathrm{s} ; 10 \mathrm{~Hz})$ to induce the oxidation and reduction of catecholamines at the tip of the recording electrode. Dopamine's signature oxidation and reduction peaks, which occur at approximately $+0.6 \mathrm{~V}-0.2 \mathrm{~V}$, respectively, were used to identify dopamine. c. Stimulation of the PPTg increases cocaine-evoked dopamine concentration in the NAc. Averaged peak responses of PPtg-evoked dopamine before and $10 \mathrm{~min}$ after cocaine $(10 \mathrm{mg} / \mathrm{kg}$, ip). Bars represent mean $\pm \mathrm{SEM}$. Open circles overlaying bars represent individual responses. d. Current time plot and E. color plot of PPTg-evoked dopamine in the absence or right, presence of IP cocaine. 
relative to bregma: $8.0 \mathrm{~mm}$ posterior, $1.5 \mathrm{~mm}$ lateral, $-7.0 \pm 0.4 \mathrm{~mm}$ ventral) in $0.2 \mathrm{~mm}$ increments. At each increment, a train of current pulses (60 pulses, $4 \mathrm{~ms}$ per pulse, $60 \mathrm{~Hz}$ ) was delivered. Dopamine was identified by its characteristic oxidation and reduction potentials, which occur at approximately +0.6 and $-0.2 \mathrm{~V}$ respectively (vs. $\mathrm{Ag} / \mathrm{AgCl}$ ). The position of the stimulating electrode was optimized for maximal release.

\section{Insulin administration in FSCV}

A within-subjects analysis was used to assess changes in dopamine responses following vehicle or insulin administration. Peak signal (nA) following PPTg stimulation (every $5 \mathrm{~min}$ ) was recorded prior to and following drug administration. To establish baseline dopamine responses, a minimum of four stimulations with peak responses falling within $10 \%$ of one another were required. For intra-VTA drug administration, an injector, which extended $1 \mathrm{~mm}$ past the tip of the cannula, was attached to tubing and a Hamilton syringe. Drugs were injected at a rate of $100 \mathrm{~nL}$ per min. Insulin $\left(\mathrm{Zn}^{2+}\right.$ free, Sigma Aldrich) was dissolved in $10 \%$ dimethylsulfoxide (DMSO) and sterile saline to obtain final concentrations of 1 and $100 \mathrm{~nm}$ (350 nL injected). S961 (Phoenix Pharmaceuticals) was dissolved in sterile saline $(0.595 \mu \mathrm{M})$ and microinjected immediately prior to insulin. Cocaine hydrochloride (Toronto Research Chemicals) was dissolved in saline and administered intraperitoneally (IP) at a dose of $10 \mathrm{mg} / \mathrm{kg}$ of body weight.

\section{Locomotor responses to cocaine}

To examine whether intra-VTA insulin administration alters locomotor responses to cocaine, rats were implanted with 22 gauge bilateral cannulas aimed at the VTA (Plastics One, relative to bregma: $-5.6 \mathrm{~mm}$ posterior, $\pm 0.5 \mathrm{~mm}$ lateral, $-7.0 \mathrm{~mm}$ ventral). Surgical procedures were conducted under isoflurane anesthesia and performed using a Kopf stereotaxic apparatus (Tujunga California). Rats were treated with subcutaneous ketoprofen (Anafen ${ }^{\circledR}$, $5 \mathrm{mg} / \mathrm{kg}$ body weight) as needed and were allowed 7 days to recover prior to behavioral testing. Locomotor responses were measured during the light phase of the light/dark cycle in $60 \times 47 \mathrm{~cm}$ locomotor chambers and Any-Maze software was used to assess locomotion (distance travelled in meters). On the test day, rats were allowed to habituate to the chambers for $30 \mathrm{~min}$ (baseline) and given an intra-VTA infusion of insulin or vehicle (100 nм insulin, $350 \mathrm{~nL} /$ hemisphere at a rate of $100 \mathrm{~nL} / \mathrm{min}$ ) using a bilateral injector extending $1 \mathrm{~mm}$ past the guide cannula. Twenty minutes later, rats were administered cocaine $(10 \mathrm{mg} / \mathrm{kg}$, intraperitoneal (i.p.) described above) or saline (0.9\%, i.p.) and locomotion was recorded for an additional $90 \mathrm{~min}$. Cannula placements were verified at the end of the experiment and are presented in Fig. 4b.

\section{Intranasal insulin administration, locomotor activity and blood glucose testing}

Male and female P60 DAT ${ }^{\text {IREScre }}$ :TdTomato mice bred in house $($ Jax stock $006660 \times 007914($ Ai140)) were habituated to intranasal delivery and handled prior to testing. We used mice instead of rats for these experiments as we had more consistent success with intranasal insulin administration due to the availability of protocols for mice (Hanson et al., 2013). Insulin $(5 \mu \mathrm{g} / \mu \mathrm{L}$ insulin in $10 \%$ DMSO and saline, $15 \mu \mathrm{L} /$ nare) or vehicle (10\% DMSO and saline, $15 \mu \mathrm{L} /$ nare) was administrated intranasally via a modified protocol (Hanson et al., 2013). Delivery was administered without anesthesia while animals were held in a supine position. After intranasal treatment, animals were placed in their home cage for $30 \mathrm{~min}$ prior to cocaine administration and open-field test. In some experiments, S961 $(1 \mu \mathrm{g} /$ $200 \mathrm{~nL}$ per hemisphere at $0.1 \mu \mathrm{L} / \mathrm{min}$ ) or vehicle (saline) was infused into the VTA via a guide cannula (mouse VTA: relative to bregma: $3 \mathrm{~mm}$ posterior, $\pm 0.5 \mathrm{~mm}$ medio-lateral, $4.45 \mathrm{~mm}$ ventral; injectors extended $1 \mathrm{~mm}$ past the guide cannula), $5 \mathrm{~min}$ prior to intranasal insulin. After $30 \mathrm{~min}$, mice received cocaine $(15 \mathrm{mg} / \mathrm{kg}$, i.p.) or saline $(0.9 \%$, i.p.). Mice were then placed in an open-field apparatus and tracked via AnyMaze software for $30 \mathrm{~min}$. In separate experiments, mice were habituated to intranasal administration and handled prior to testing. Baseline blood glucose levels were measured from tail blood using an Accu-Check Aviva blood glucose monitor. Mice then received insulin $(5 \mu \mathrm{g} / \mu \mathrm{L}$ insulin in $10 \%$ DMSO and saline, $15 \mu \mathrm{L} /$ nare) or vehicle (10\% DMSO and saline, $15 \mu \mathrm{L} /$ nare) via intranasal application. Animals were placed back into their home cage and tail blood was taken 30 and 60 min post intranasal condition for glucose measurement.

\section{Data analysis}

Data represent peak signals for each stimulation and are expressed as a percent of baseline (mean of four stimulations prior to drug administration). Data were analyzed and graphs were generated in Prism 6 software (GraphPad). Unless otherwise indicated, data met the assumptions of equal variances. To test for statistical significance, Student's $t$-test, one-way and two-way ANOvas were performed and Dunnett's multiple comparison test when comparing to a control group or Sidak's post hoc analysis were carried out as needed. The sample size is expressed as $N$ (number of animals) and the levels of significance are indicated as followed: **** $P<0.0001,{ }^{* * *} P<0.001,{ }^{* *} P<0.01,{ }^{*} P<0.005$.

\section{Results}

\section{Intra-VTA insulin administration reduces PPTg-evoked NAC dopamine release}

We initially verified that PPTg stimulation reliably evokes dopamine in the NAc (Fig. 1; Ehrich et al., 2014). This effect was potentiated by cocaine $\left(10 \mathrm{mg} / \mathrm{kg}\right.$, i.p.; $t_{(6)}=5.15 ; P=0.0015$; Fig. 1b,d,e). To determine if insulin administered in the VTA modulated dopamine release in the NAc, we phasically stimulated PPTg inputs to the VTA, while delivering insulin in the VTA via an implanted cannula and recording dopamine concentration in the NAc using FSCV (Fig. 2). These experiments were performed in anesthetized ad libitum fed rats approximately $4-5 \mathrm{~h}$ into their light phase to minimize meal-induced elevated endogenous insulin levels (Labouèbe et al., 2013; Liu et al., 2016). After four stable PPTg-evoked dopamine recordings, vehicle, $1 \mathrm{~nm}$ or $100 \mathrm{~nm}$ insulin was microinjected into the VTA via an implanted cannula. Peak NAc dopamine responses decreased over time (Fig. 2a, $\left.F_{12,259}=11.57, P<0.0001\right)$ and differed between experimental groups $\left(F_{2,259}=25.22, P<0.0001\right)$. Furthermore, the two-way ANOVA revealed a significant time $\mathrm{x}$ group interaction $\left(F_{24,259}=2.87, P<0.0001\right)$. A Dunnett's multiple comparison test revealed that both concentrations of insulin reduced NAc dopamine responses $(P=0.0001$, compared to vehicle). $100 \mathrm{~nm}$ insulin significantly decreased dopamine within $15 \mathrm{~min}$ of intra-VTA administration (v: $100 \pm 5.1 \%, 1 \mathrm{nM:} 93 \pm 4 \%, 100 \mathrm{nm:} 76 \pm 4 \%$ of baseline; one-way anova $\left(F_{2,20}=7.71, P=0.0033\right.$, Dunnet's post 
hoc test, $100 \mathrm{~nm}$ compared to vehicle: $P<0.01$; Fig. $2 \mathrm{~b}$ ). IntraVTA insulin effects on NAc dopamine were long lasting, such that after $105 \mathrm{~min}$, dopamine responses were of $61 \pm 9 \%$ (1 nM insulin) and $59 \pm 3 \%$ (100 nм insulin) of baseline (Fig. 2c, one-way ANOVA $\left(F_{2,19}=8.37, P=0.0025\right.$, Dunnett's post hoc test all compared to vehicle, $1 \mathrm{~nm} P<0.01,100 \mathrm{~nm} P<0.01$ ), indicating that $1 \mathrm{~nm}$ is likely a saturating concentration of insulin in the VTA. Taken together, intra-VTA insulin at $1 \mathrm{~nm}$ and $100 \mathrm{~nm}$ suppressed PPTg-evoked NAc dopamine.

Insulin receptors (Figlewicz et al., 2003; Liu et al., 2013) and insulin-like growth factor receptors are expressed in the VTA (Vigneri et al., 2010). Therefore, we tested the necessity of VTA insulin receptor activation in the inhibition of evoked NAc dopamine release by intra-VTA insulin. The insulin receptor antagonist, S961, is a high-affinity peptide that does not penetrate the cell membrane and therefore binds to the extracellular portion of the receptor, likely preventing dimerization of the insulin receptor (Schäffer et al., 2008). Intra-VTA administration of S961 infused over $2 \mathrm{~min}$ immediately prior to insulin, blocked intra-VTA insulin-induced suppression of NAc dopamine release (Fig. 2d). Averaged maximal-evoked dopamine responses at $105 \mathrm{~min}$ after intra-VTA insulin alone was significantly different compared to insulin and S961 (Fig. 2d, $T_{6}=3.11, P=0.021$ ). Thus, insulinmediated suppression of NAc dopamine requires intra-VTA insulin receptor activation.

\section{Intra-VTA insulin administration reduces PPTg-evoked NAc dopamine responses to cocaine}

The psychostimulant drug, cocaine, induces its locomotor-activating and reinforcing effects by increasing NAc dopamine concentration (Di Chiara \& Imperato, 1988). Cocaine rapidly potentiates excitatory inputs onto dopamine neurons (Argilli et al., 2008; Zweifel et al., 2008). Cocaine-mediated enhancement of excitatory synaptic transmission onto dopamine neurons can increase burst firing (Creed et al., 2016). To examine whether insulin in the VTA blocks cocaine-potentiated NAc dopamine, intra-VTA insulin was administered prior to or following a systemic cocaine injection (a)

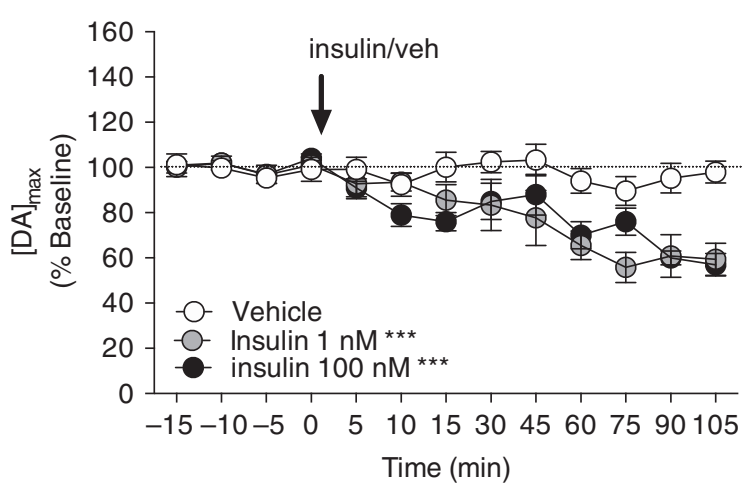

(c)

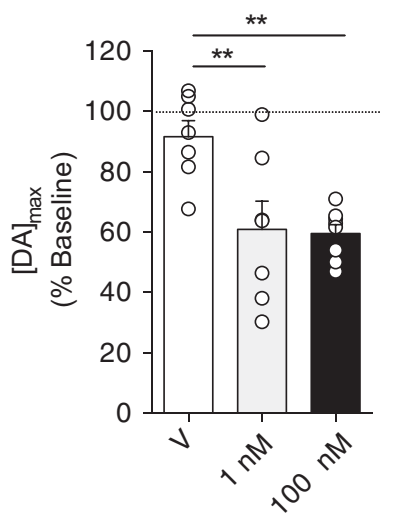

(b)

Short term

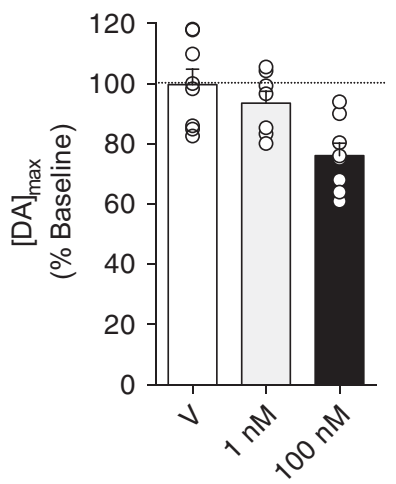

(e)

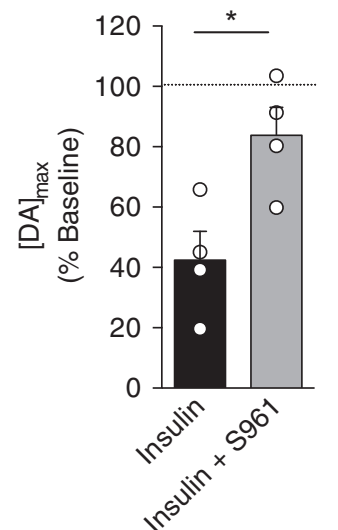

FIG. 2. Intra-VTA insulin administration reduces PPTg-evoked NAc dopamine release. a. Mean peak dopamine responses recorded prior to and following intra-VTA administration of vehicle ( $n=9$, open circles), $1 \mathrm{~nm}$ insulin $(n=8$, shaded circles) or $100 \mathrm{~nm}$ insulin $(n=8$, filled circles). Intra-VTA administration of $1 \mathrm{~nm}$ and $100 \mathrm{~nm}$ significantly decreased peak NAc dopamine responses compared to vehicle treatment (Dunnett's multiple comparison test $P=0.0001 * * *$ for $1 \mathrm{~nm}$ and $100 \mathrm{~nm}$ vs. vehicle). Arrow refers to the time insulin was delivered to the VTA. b. Averaged peak [DA] at the last 15 min time point post insulin microinjection (Dunnett's multiple comparison test: $1 \mathrm{~nm} P>0.05,100 \mathrm{~nm} P<0.01^{* *}$ ). c. Averaged peak [DA] $]_{\mathrm{o}}$ at the last stimulation (Dunnett's multiple comparison test: 1 nм $P<0.01^{* *}, 100$ nм $P<0.01^{* *}$ ). d. Example traces of PPtg-evoked dopamine before (hashed line) and after (solid line) 100 nm insulin in the absence (i) or presence (ii) of S961. e. Intra-VTA administration of the insulin receptor antagonist, S961, immediately prior to insulin $(n=5$, shaded bars) blocked the decrease in dopamine release observed with intra-VTA insulin and vehicle $(n=4$, filled bars) administration. Average evoked dopamine responses from the last two stimulations are significantly different with administration of insulin alone compared to insulin and S961 $\left(t\right.$-test, $\left.P=0.033^{*}\right)$. Open circles overlaying bars represent individual responses. Bars represent mean \pm SEM. 
$(10 \mathrm{mg} / \mathrm{kg}$, i.p.). To test if pre-administration of insulin could suppress cocaine-evoked dopamine, intra-VTA insulin was delivered 15 min prior to systemic cocaine as we observed a significant insulin-mediated suppression of dopamine at this time point (Fig. 2b). To determine if intra-VTA insulin suppresses dopamine after cocaine-mediated potentiation of dopamine, we administered insulin $8 \mathrm{~min}$ after systemic cocaine because we expected a maximal cocaine-mediated potentiation of dopamine after 5 min (España et al., 2011) and we wanted to deliver intra-VTA insulin prior to the FSCV recording at $10 \mathrm{~min}$. Intra-VTA administration of insulin 15 min prior to cocaine reduced cocaine-potentiated evoked NAc dopamine compared to intra-VTA vehicle administration prior to cocaine (two-way ANOva: time effect $\left(F_{15,224}=4.93, P<0.0001\right.$ ), insulin vs. vehicle effect $\left(F_{1,224}=45.34, P<0.0001\right)$, time $\mathrm{x}$ group interaction $\left(F_{15,224}=2.65, P=0.001\right)$; Fig. 3a). Maximal dopamine responses following cocaine administration were abolished in the presence of intra-VTA insulin (cocaine effect $\left(F_{1,14}=27.46, \quad P=0.0001\right) ; \quad$ insulin $\quad$ effect $\quad\left(F_{1,14}=7.27\right.$ $P=0.017)$; cocaine $\times$ insulin interaction $\left(\mathrm{F}_{1,14}=7.47, P=0.016\right)$
Fig. 3a,b). A Sidak's post hoc test revealed that while cocaine administration significantly increased maximal dopamine concentrations in animals pre-treated with intra-VTA vehicle $(178 \pm 16 \%$ from baseline, $P<0.0001$ ), this increase is not observed with intra-VTA insulin pre-treatment $(124 \pm 10 \%$ from baseline, $P>0.05)$. Thus, intra-VTA insulin decreases cocaine-potentiated dopamine in the NAc.

To determine if intra-VTA insulin delivered after cocaine administration influences evoked NAc dopamine, we administered intraVTA insulin 8 min following systemic cocaine exposure. Intra-VTA insulin significantly reduced evoked dopamine compared to intraVTA vehicle when administered after cocaine [Fig. 3c,d, time effect $\left(F_{15,256}=24.68, \quad P<0.0001\right) ; \quad$ insulin effect $\left(F_{1,256}=5.37\right.$, $P=0.02)$, interaction $\left.\left(F_{15,256}=1.54, P=0.09\right)\right]$. Vehicle- and insulin-treated rats show a significant effect of cocaine on maximal dopamine responses [Fig. 3d, cocaine effect $\left(F_{1,16}=133.8\right.$, $P<0.0001)$; insulin effect $\left(F_{1,16}=3.86, \quad P=0.07\right)$; interaction $\left.\left(F_{1,16}=3.86, \quad P=0.07\right)\right]$, with vehicle-injected rats showing a $222 \pm 15 \%$ increase and insulin-injected rats showing a
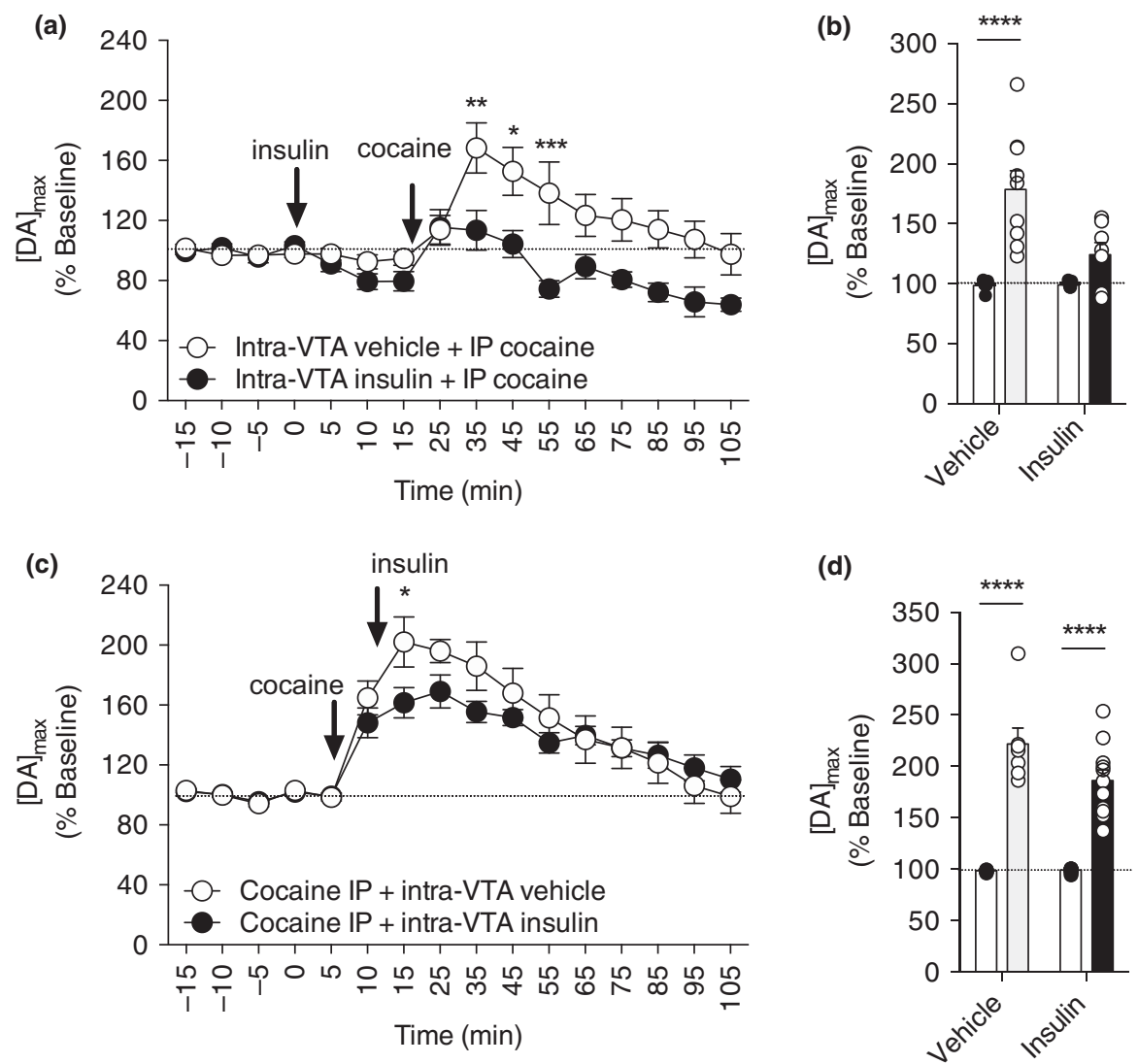

FIG. 3. Intra-VTA insulin administration reduces PPTg-evoked NAc dopamine responses to cocaine. a. Peak dopamine responses recorded prior to and following the administration of intra-VTA vehicle $(n=9$, open circles) or $100 \mathrm{~nm}$ insulin $(n=7$, filled circles $)$ and the administration of cocaine $(10 \mathrm{mg} / \mathrm{kg}$, i.p.). Intra-VTA administration of insulin $10 \mathrm{~min}$ prior to cocaine reduced cocaine-potentiated evoked NAc dopamine responses compared to intra-VTA vehicle administration (two-way ANovA, main effect of vehicle vs. insulin, $P<0.0001$ ). A Sidak's multiple comparison test indicated significant group differences at 35 $\left(P<0.01^{* *}\right), 45\left(P<0.05^{*}\right)$ and $55\left(P<0.001^{* *}\right)$ min post intra-VTA insulin. Arrows indicate administration of intra-VTA insulin $($ left $)$ or cocaine (right). b. Averaged dopamine during respective baselines (open bars (at 0 min) and maximum responses following cocaine administration (at 35 min) in animals administered intra-VTA vehicle (shaded) or $100 \mathrm{~nm}$ insulin (filled). A Sidak's post hoc test indicated a significant increase in dopamine after cocaine administration in the presence of vehicle $(P<0.0001 * * * *)$, but not insulin $(P>0.05)$. c. Dopamine responses recorded prior to and following cocaine $(10 \mathrm{mg} / \mathrm{kg}$, i.p) and intra-VTA vehicle ( $n=7$, open circles) or $100 \mathrm{~nm}$ insulin $(n=11$, filled circles). Intra-VTA insulin significantly reduced evoked dopamine compared to intra-VTA vehicle (two-way ANOVA, main effect of vehicle vs. insulin, $P=0.02$ ). A Sidak's multiple comparison test indicated significant group differences at 15 min post cocaine administration $\left(P<0.05^{*}\right)$. Arrows indicate injection of cocaine (left) or intra-VTA insulin (right). d. Averaged dopamine during respective baselines (open bars, at 0 min) and maximum responses following cocaine administration (at 15 min) in animals administered intra-VTA vehicle (shaded) or $100 \mathrm{~nm}$ insulin (filled). Planned comparisons indicated a significant increase of dopamine after cocaine administration in the presence of vehicle $\left(P<0.0001^{* * *}\right)$, or insulin $\left(P>0.0001^{* * * *}\right)$. Open circles overlaying bars represent individual responses. Bars represent mean \pm SEM. 
$186 \pm 10 \%$ increase from baseline. Based on the results in Fig. 3a and $\mathrm{B}$, our a priori hypothesis for this experiment was that intraVTA insulin would suppress cocaine-evoked dopamine. However, a planned comparison revealed only a trend $(P=0.06)$. Thus, even though intra-VTA insulin can inhibit cocaine-potentiated dopamine release, the timing of insulin administration is an important determinant of insulin's effect on cocaine-potentiated dopamine concentration.

\section{Intra-VTA insulin administration reduces locomotor responses to cocaine}

To examine whether intra-VTA insulin administration decreases locomotor responses to cocaine, locomotor activity was recorded prior to and following infusions of insulin or vehicle into the VTA and an i.p. injection of cocaine or vehicle (Fig. 4a). During baseline, locomotor responses rapidly decreased as the animals habituated to the open field in both the pre-cocaine and pre-saline conditions [Fig. 4c, time effect $\left.\left(F_{2,56}=52.80, P<0.0001\right)\right]$. No group differences (insulin vs. vehicle) were observed during the baseline $\left(F_{1,56}=0.76, P=0.53\right)$. Cocaine maximally increased locomotor activity $20 \mathrm{~min}$ post injection in vehicle treated rats [Fig. 4c, time effect $\left.\left(F_{8,224}=7.89, P<0.0001\right)\right]$. There was a significant main effect of insulin $\left(F_{3,28}=3.615, \quad P=0.025\right.$; interaction: $\left.F_{24,224}=2.91, \quad P<0.0001\right)$. Sidak's multiple comparison tests revealed that locomotor responses to cocaine after intra-VTA insulin were significantly different than after intra-VTA vehicle at $20 \mathrm{~min}$ $(P=0.0032)$. Similarly, at this time point, locomotor responses between cocaine and saline after intra-VTA vehicle were significantly different $(P<0.0001)$. Averaged locomotor activity (over $90 \mathrm{~min}$ ) was significantly greater after cocaine compared to baseline (over $30 \mathrm{~min}$; Two-way ANOvA, time effect: $F_{1,28}=9.315$, $P=0.0049$, insulin effect; $F_{3,28}=2.34, P=0.09$; interaction: $F_{3,28}=4.78, P=0.0082$ ). A Sidak's multiple comparison test indicated that intra-VTA insulin administration significantly reduced locomotor activity to cocaine $(P=0.02$, Fig. $4 d)$. Intra-VTA insulin did not significantly change locomotor activity in the saline-treated animals $(P<0.05)$. Taken together, intra-VTA insulin did not alter baseline locomotor activity during habituation or in the saline condition, but intra-VTA insulin decreased cocaine-induced locomotor activity.

FIG. 4. Intra-VTA insulin administration reduces locomotor responses to cocaine. a. Locomotor responses were measured prior to (baseline, $30 \mathrm{~min}$ ) and following (test, $90 \mathrm{~min})$ intra-VTA infusions of insulin $(100 \mathrm{~nm} ; n=8)$ or vehicle $(n=8)$ followed 20 min later by i.p. injections of saline $(0.9 \%)$ or cocaine $(10 \mathrm{mg} / \mathrm{kg})$. b. Location of cannula placements in the VTA (intraVTA insulin + cocaine group) mapped onto illustrations from the rat brain atlas of Paxinos and Watson (2007). c. Locomotor responses prior to (baseline, 0-30 $\mathrm{min})$ and following cocaine $(10 \mathrm{mg} / \mathrm{kg}, 0-90 \mathrm{~min})$ in animals pretreated with intra-VTA insulin (100 nM, $n=8$, filled circles) or vehicle ( $n=8$, open circles) or saline (i.p., $0-90 \mathrm{~min})$ in rats pre-treated with intraVTA insulin (100 nM, $n=8$, filled triangles) or vehicle ( $n=8$, open triangles). Insulin significantly reduced locomotor responses at $20 \mathrm{~min}$ post cocaine administration (Sidak's multiple comparison test $P<0.05^{*}$ ). No group differences were observed during baseline $(P>0.05)$. D. Averaged locomotion during baseline (over $30 \mathrm{~min}$; open bars) and following cocaine (filled bars) or saline (shaded bars) administration (over $90 \mathrm{~min}$ ) in the presence of intra-VTA vehicle or insulin. Intra-VTA insulin significantly reduced cocaine-induced locomotion (Sidak's multiple comparison test, $P<0.05^{*}$ ). Locomotor responses prior to (open bars) and following vehicle $(P>0.05)$ or insulin (shaded bars; $P>0.05$ ) did not significantly alter locomotor responses to saline. Open circles overlaying bars represent individual responses. Bars represent mean $\pm \mathrm{SEM}$.

\section{Intranasal insulin suppresses cocaine-induced locomotor activity}

In humans, intranasal insulin can modulate resting state imaging of activity in brain regions involved in reward processing (Kullmann et al., 2013; Heni et al., 2016) and attenuates visual processing of food images (Guthoff et al., 2010). After intranasal insulin administration, insulin enters the brain via several pathways including the

(a)

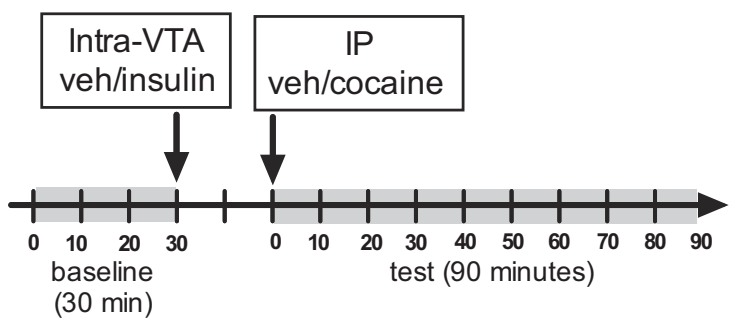

(b)

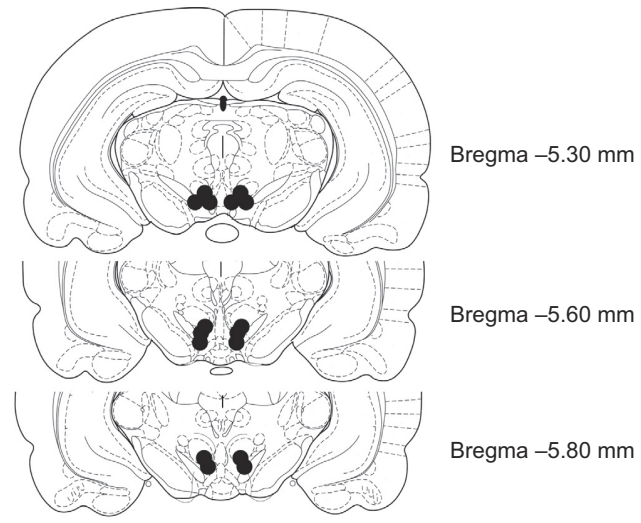

(c)
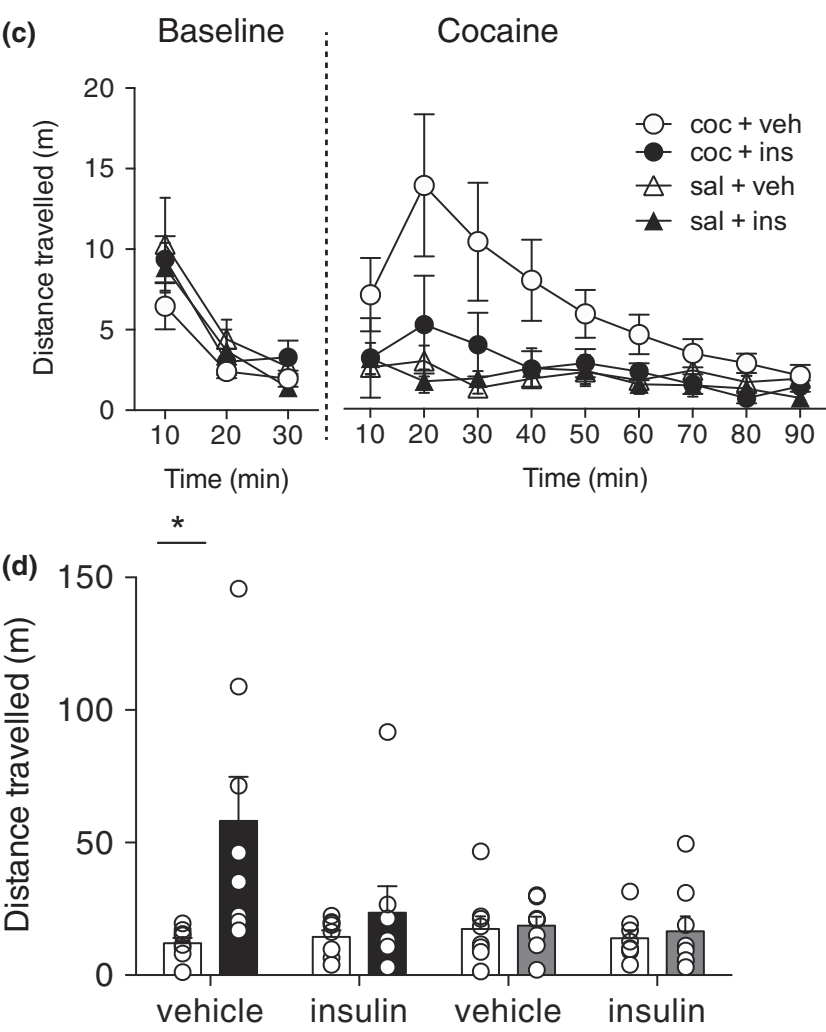

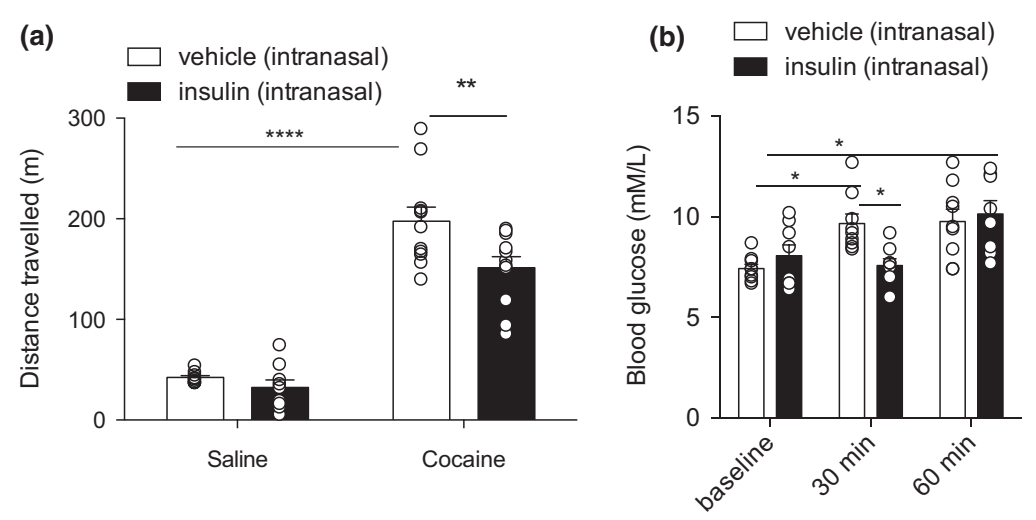

(c)
- vehicle (intranasal) + intra-VTA S961
(c) - insulin (intranasal) + intra-VTA s961
$\square$ vehicle (intranasal) + intra-VTA vehicle
$\bigcirc$ insulin (intranasal) + intra-VTA vehicle

(d)
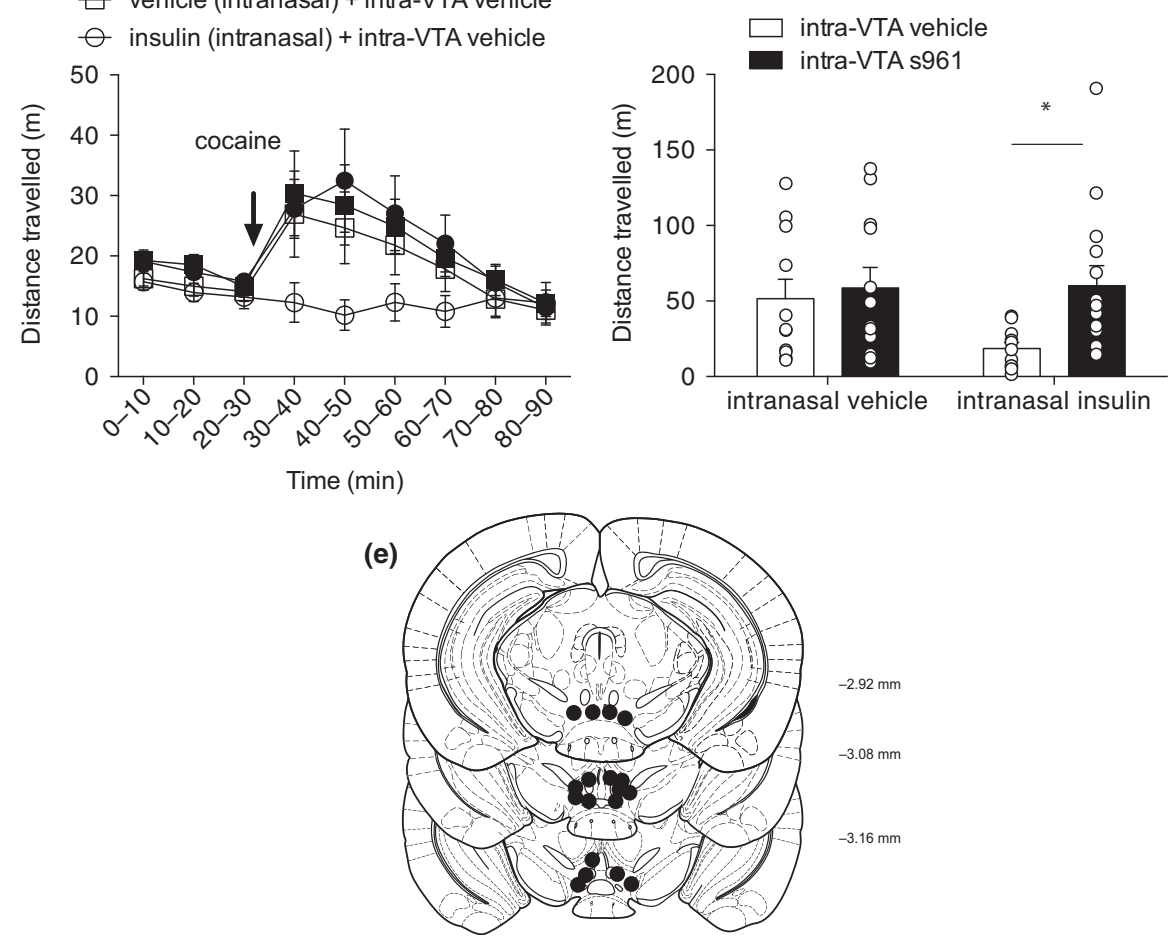

FIG. 5. Intranasal insulin suppresses cocaine-evoked locomotor activity. Insulin $(15 \mu \mathrm{L} / \mathrm{nare}, 5 \mu \mathrm{g} / \mathrm{mL})$ or vehicle $(15 \mu \mathrm{L} /$ nare $)$ was administered intranasally to mice $30 \mathrm{~min}$ prior to an i.p. injection of cocaine $(15 \mathrm{mg} / \mathrm{kg}, n=11)$ or saline $(0.9 \%, n=9)$. a. Averaged locomotor activity over $30 \mathrm{~min}$ in the presence of saline or cocaine after intranasal administration of insulin (filled bars) or vehicle (open bars). A Sidak's multiple comparison test revealed a significant change in locomotor activity between intranasal vehicle and insulin in the presence of cocaine $\left(P<0.01^{* *}\right)$, but not saline $(P>0.05)$. b. Blood glucose was assessed at 30 or 60 min after intranasal insulin (filled bars) or saline (open bars) administration. A Sidak's multiple comparison test revealed a significant effect of insulin on plasma glucose at $30 \mathrm{~min}\left(P<0.05^{*}\right)$, but at no other time point. c. Time course of the effects of the intra-VTA insulin receptor antagonist, S961 (1 $\mu \mathrm{g}$; filled symbols) or vehicle (open symbols) on cocaine-induced locomotor activity after intranasal insulin [circles $(n=11$, vehicle; $n=14$, S961)] or vehicle [squares $(n=11$, vehicle; $n=12$, S961)]. Intra-VTA S961 or vehicle was delivered 5 min prior to intranasal administration of insulin or vehicle. Cocaine was delivered $30 \mathrm{~min}$ after intranasal administration. d. Distance travelled averaged over $10 \mathrm{~min}$ recorded $10 \mathrm{~min}$ after administration of cocaine. Intranasal insulin with intra-VTA vehicle significantly suppressed cocaine-induced locomotor activity $(P<0.05)$. However, there was no suppression of cocaine-induced locomotor activity in the presence of intranasal insulin and S961. E. Location of cannula placements in the VTA (intra-VTA vehicle or S961 groups) mapped onto illustrations from the rat brain atlas of Paxinos and Watson (2007). Open circles overlaying bars represent individual responses. Bars represent mean \pm SEM.

olfactory- and trigeminal-associated extracellular pathways, the cerebrospinal fluid and the perivascular pathway (Dhuria et al., 2010). While intranasal insulin delivery to mice does not affect odorant threshold, it can evoke anxiolytic behavior and enhance short and long-term object memory recognition (Marks et al., 2009). Therefore, we tested if intranasal delivery can influence cocaine-induced locomotor activity. Cocaine significantly increased locomotor activity (two-way ANova, cocaine effect: $F_{1,36}=170.9, \quad P<0.0001$;
Fig. 5a). There was a significant main effect of intranasal insulin $\left(F_{1,36}=7.17, \quad P=0.011 ; \quad\right.$ interaction: $\left.F_{1,36}=3.03, \quad P=0.09\right)$. Planned comparisons indicated that insulin significantly decreased cocaine-induced locomotor activity $(P=0.017)$, but did not alter locomotor activity in the presence of saline $(P=0.22)$. To test if intranasal insulin altered blood glucose, we measured glucose concentration from tail blood at 30 and $60 \mathrm{~min}$ after intranasal insulin application. There was a main effect of time on blood glucose 
concentration (time effect: $F_{2,30}=16.55, P<0.0001$; Fig. 5b), suggesting that blood glucose levels increased over time. While there was no main effect of insulin on blood glucose (insulin effect: $F_{1,15}=0.44, \quad P=0.52 ; \quad$ interaction: $F_{2,30}=7.575, \quad P=0.0022$; Fig. 5b), a Sidak's multiple comparison test indicated that intranasal insulin suppressed blood glucose at $30(P<0.05)$ but not 60 $(P>0.05)$ min. We then tested if the intranasal insulin-mediated suppression of cocaine-induced locomotor activity was mediated by insulin receptor activation in the VTA. Consistent with our previous results, intranasal insulin suppressed cocaine-induced locomotor activity in intra-VTA vehicle administered mice (Fig. 5c). This suppression was blocked by intra-VTA S961, an insulin receptor antagonist (Fig. 5C). When comparing the distance traveled 10 min after cocaine, there was a significant main effect of intra-VTA treatment on locomotor activity $\left(F_{1,44}=4.162 ; \quad P=0.04\right.$; interaction: $F_{1,44}=2.068, P=0.15$; Fig. 5 d). Planned comparisons indicated a significant difference of locomotor activity between intra-VTA vehicle and intra-VTA S961 with intranasal insulin administration $(P=0.01)$, but not intranasal vehicle administration $(P=0.7$; Fig. 5d). Taken together, these results indicate that intranasally administered insulin suppressed cocaine-induced locomotor activity without having long-term effects on peripheral glucose concentration. Insulin-mediated suppression of locomotor activity was mediated by insulin action in the VTA.

\section{Discussion}

In the present study, we demonstrate that insulin in the VTA reduced NAc dopamine release in vivo, an effect that is dependent on activation of insulin receptors. We also demonstrate that insulin in the VTA attenuated cocaine-potentiated NAc dopamine as well as locomotor responses to cocaine. Cocaine-induced locomotor activity was also suppressed with intranasal insulin.

Insulin administration in the VTA reduced PPTg-evoked dopamine release in the NAc. Previous work in midbrain slices has demonstrated that insulin decreases somatodendritic dopamine concentration (Mebel et al., 2012) or striatal dopamine concentration (Patterson et al., 1998; Williams et al., 2007; Daws et al., 2011; Speed et al., 2011) via an upregulation of dopamine transporters. However, insulin action in striatal slices has also been shown to increase (Stouffer et al., 2015) or decrease (Cai et al., 2018) terminal dopamine release. In one study, insulin (1 nM) application to striatal slices increases acetylcholine release from striatal cholinergic interneurons, which promotes dopamine release from terminals (Stouffer et al., 2015). In the other study, insulin (100 nм) acts at insulin receptors on striatal astrocytes to increase purine release that, in turn, acts on striatal terminals to decrease dopamine release (Cai et al., 2018). Indeed, it has been proposed that higher-striatal insulin concentration can decrease dopamine whereas a lower-insulin concentration can increase dopamine concentration at striatal terminal (Stouffer et al., 2015). It is important to note that the $K_{d}$ of insulin at its receptor is $\sim 1 \mathrm{~nm}$ and insulin levels in CSF, plasma or brain homogenates are estimated to be below 30 nм (Havrankova et al., 1978; Strubbe et al., 1988; Banks \& Kastin, 1998). We demonstrate that insulin action in the VTA at a higher (100 nM) or lower (1 nM) concentration can inhibit NAc dopamine in vivo. Thus, it is possible that either concentration is capable of initiating a cascade of events in the VTA that induces a long-lasting depression of evoked dopamine concentration. Our findings are consistent with in vivo chronoamperometry studies showing decreased dopamine clearance in rat striatum in hypoinsulinemic (Owens et al., 2005) or food restricted (Sevak et al., 2008) rats.
We observed an immediate and long-lasting action of insulin on NAc dopamine. The insulin receptor antagonist, S961, administered in the VTA blocked the long-acting insulin-induced decrease in NAc dopamine, suggesting these effects are initiated by VTA insulin receptor activation. Because insulin is rapidly metabolized or cleared from the extracellular space, long-lasting mechanisms may be engaged by insulin receptor signaling that do not necessarily require continued action at insulin receptors. Insulin acting at insulin receptors on VTA dopamine neurons induces an endocannabinoidmediated long-term depression at excitatory synapses by reducing the probability of pre-synaptic glutamate release (Labouèbe et al., 2013). Meal-induced insulin release suppresses excitatory synaptic transmission in the VTA lasting up to $3 \mathrm{~h}$ (Labouèbe et al., 2013). Thus, this mechanism may contribute to the long-lasting intra-VTA insulin-induced suppression of NAc dopamine.

Intra-VTA suppression of NAc dopamine may require burst firing of dopamine neurons. Electrical stimulation of the PPTg induces glutamate and acetylcholine release at terminals in the VTA and thus, can pre-synaptically drive burst firing in dopaminergic neurons and phasic dopamine release (Floresco et al., 2003; Zweifel et al., 2009). Given that we observed an insulin-induced suppression of PPTg-evoked NAc dopamine, it is possible that burst firing of dopamine neurons may be a requirement for insulin to modulate the output of dopamine neurons and insulin may act by inhibiting PPTg-evoked glutamate release. Because insulin suppresses pre-synaptic glutamate release onto VTA dopamine neurons (Labouèbe et al., 2013), one can speculate that decreased glutamate release probability of PPTg inputs to the VTA may result in decreased phasic dopamine release. This mechanism would likely fit with the long-lasting time course of insulininduced suppression of dopamine release, such that the effect continues long after the likely metabolism or diffusion of insulin in the VTA. Further study will determine if PPTg glutamatergic inputs to the VTA express pre-synaptic cannabinoid receptors and if they are influenced by intra-VTA insulin.

Intra-VTA insulin suppressed cocaine-potentiated evoked dopamine release. This effect was greater when intra-VTA insulin was delivered prior to cocaine administration. One can speculate that by inhibiting PPTg inputs in the VTA and inducing a long-term depression of excitatory synaptic transmission onto dopamine neuron, insulin suppresses dopamine neuronal burst firing, thus reducing phasic NAc dopamine concentration. Because phasic dopamine release induced by burst firing is more responsive to dopamine uptake inhibitors than tonic release (Floresco et al., 2003), cocaine's effect at dopamine terminals in the NAc is diminished. However, when intraVTA insulin is administered after cocaine, insulin's inhibitory effect on NAc dopamine may be reduced because the cocaine-mediated reuptake inhibition at axon terminals in the NAc outweighs insulin's ability to alter phasic dopamine release.

Cocaine's ability to potentiate locomotion is directly related to the amount of dopamine released in the striatum (Di Chiara \& Imperato, 1988). We therefore hypothesized that insulin administered directly into the VTA prior to cocaine administration would decrease locomotor responses. Indeed, dampened locomotor responses to cocaine were observed in rats pre-treated with intraVTA insulin. To further support this finding, inhibition of insulin receptors in the VTA reversed the inhibitory effect of intranasal insulin on cocaine-induced locomotor activity. Thus, insulin directly targets the VTA to reduce cocaine-potentiated NAc dopamine release and locomotor responses. In contrast to our results, congenital deletion of insulin receptors in TH-expressing neurons blunted locomotor responses to cocaine in mice (Könner et al., 2011). However, it is difficult to interpret these findings as insulin 
receptors were deleted from all dopaminergic and noradrenergic cells in these mice. Thus, the blunted locomotor activity in these mice may be due to altered insulin signaling in catecholaminergic regions other than the VTA or due to altered development of catecholaminergic circuits due to a loss of insulin signaling in these regions throughout development.

Intranasal insulin also suppressed cocaine-induced locomotor activity, suggesting a potential therapeutic opportunity. Indeed, intranasal insulin decreases craving for smoking nicotine in humans (Hamidovic et al., 2017). Notably, intranasal administration of vehicle modestly increased peripheral glucose concentration. This effect may be due to elevated corticosterone-induced gluconeogenesis due to the handling procedure. Intranasal insulin briefly decreased peripheral glucose concentration compared to vehicle only at the $30 \mathrm{~min}$ time point. However, this effect was not different from baseline blood glucose, suggesting that insulin may suppress corticosteroneinduced increases in peripheral glucose. Alternatively, hypothalamic and striatal insulin signaling can suppress endogenous glucose production in humans (Heni et al., 2017), so perhaps this mechanism can also occur in rodents. In summary, intranasal or intra-VTA insulin reduces cocaine-induced locomotor activity. Because insulin also enhances trafficking of cocaine-sensitive monoamine transporters DAT and NET (Daws et al., 2011), and reduces impulsive behavior in the NAc (Schoffelmeer et al., 2011), insulin may provide a novel therapeutic for targeting inhibitory control disorders including addiction and obesity.

In conclusion, intra-VTA insulin suppressed-evoked dopamine in the NAc, an effect that is blocked by inhibiting insulin receptor signaling in the VTA. Because stimulation of PPTg inputs contribute to phasic dopamine release (Floresco et al., 2003; Zweifel et al., 2009), and phasic dopamine underlies reward-associated stimuli (Wanat et al., 2009), intra-VTA insulin suppression of PPTg evoked-dopamine may underlie insulin-mediated inhibition of conditioned place preference for food, anticipatory food seeking, sucrose self-administration and sated feeding of palatable food (Figlewicz et al., 2007; Bruijnzeel et al., 2011; Mebel et al., 2012; Labouèbe et al., 2013). Furthermore, insulin-induced LTD in the VTA (Labouèbe et al., 2013) may underlie the long-lasting depression of dopamine concentration in the NAc by impairing the ability of these neurons to induce burst firing. Pretreatment of insulin blocks cocaine-potentiated evoked NAc dopamine concentration. Intranasal insulin suppresses activation of the prefrontal cortex during food-related cues (Kullmann et al., 2013), decreases nicotine craving (Hamidovic et al., 2017) in humans, and decreases motor impulsivity in rodents (Schoffelmeer et al., 2011) suggesting that insulin may inhibit food or drug cravings. Therefore, it will be interesting to determine if intranasal insulin can suppress attention to drug-related cues in cocaine addicts due to insulin's ability to inhibit cocaine-potentiated evoked dopamine release.

\section{Acknowledgements}

We would like to thank Dr. Stefan Sanberg and Dr. Paul Phillips for their assistance in training members of the Borgland lab on fast scan cyclic voltammetry.

\section{Conflict of Interest}

The authors declare no competing financial interests.

\section{Data accessibility}

Data will be made available upon request. Please contact the corresponding author.

\section{Author Contribution}

LN, CL, JH performed in vivo voltammetry experiments and analyzed the data, LN and LS performed behavioral experiments and analyzed the data. LN, LS and SLB designed the study and drafted the manuscript.

\section{Abbreviations}

FSCV, fast scan cyclic voltammetry; GLP-1, glucagon like peptide 1; i.p., intraperitoneal; NAc, nucleus Accumbens; PPTg, pedunculopontine nucleus; $\mathrm{TH}$, tyrosine hydroxylase; VTA, ventral tegmental area.

\section{Funding}

This research was supported by postdoctoral awards to Lindsay Naef from Les Fonds de la Recherche en Sante du Quebec, Alberta Innovates Health Solutions and the Canadian Institute for Health Research (CIHR). This research was supported by CIHR operating grants (MOP 102617 and FDN147473) to SLB.

\section{References}

Abizaid, A., Liu, Z.-W., Andrews, Z.B., Shanabrough, M., Borok, E., Elsworth, J.D., Roth, R.H., Sleeman, M.W. et al. (2006) Ghrelin modulates the activity and synaptic input organization of midbrain dopamine neurons while promoting appetite. J. Clin. Invest., 116, 3229-3239.

Alhadeff, A.L., Rupprecht, L.E., \& Hayes, M.R. (2012) GLP-1 neurons in the nucleus of the solitary tract project directly to the ventral tegmental area and nucleus accumbens to control for food intake. Endocrinology, 153, 647-658.

Argilli, E., Sibley, D.R., Malenka, R.C., England, P.M., \& Bonci, A. (2008) Mechanism and time course of cocaine-induced long-term potentiation in the ventral tegmental area. J. Neurosci. Off. J. Soc. Neurosci., 28, 90929100 .

Banks, W.A., \& Kastin, A.J. (1998) Differential permeability of the bloodbrain barrier to two pancreatic peptides: Insulin and amylin. Peptides, 19, 883-889.

Bassareo, V., \& Di Chiara, G. (1999) Differential responsiveness of dopamine transmission to food-stimuli in nucleus accumbens shell/core compartments. Neuroscience, 89, 637-641.

Bruijnzeel, A.W., Corrie, L.W., Rogers, J.A., \& Yamada, H. (2011) Effects of insulin and leptin in the ventral tegmental area and arcuate hypothalamic nucleus on food intake and brain reward function in female rats. Behav. Brain Res., 219, 254-264.

Cai, W., Xue, C., Sakaguchi, M., Konishi, M., Shirazian, A., Ferris, H.A., Li, M.E., Yu, R. et al. (2018) Insulin regulates astrocyte gliotransmission and modulates behavior. J. Clin. Invest., 128, 2914-2926.

Creed, M., Kaufling, J., Fois, G.R., Jalabert, M., Yuan, T., Lüscher, C., Georges, F., \& Bellone, C. (2016) Cocaine exposure enhances the activity of ventral tegmental area dopamine neurons via calcium-impermeable NMDARs. J. Neurosci. Off. J. Soc. Neurosci., 36, 10759-10768.

Daws, L.C., Avison, M.J., Robertson, S.D., Niswender, K.D., Galli, A., \& Saunders, C. (2011) Insulin signaling and addiction. Neuropharmacology, 61, 1123-1128.

Dhuria, S.V., Hanson, L.R., \& Frey, W.H. (2010) Intranasal delivery to the central nervous system: Mechanisms and experimental considerations. $J$. Pharm. Sci., 99, 1654-1673.

Di Chiara, G., \& Imperato, A. (1988) Drugs abused by humans preferentially increase synaptic dopamine concentrations in the mesolimbic system of freely moving rats. Proc. Natl. Acad.sci. USA, 85, 5274-5278.

Ehrich, J.M., Phillips, P.E.M., \& Chavkin, C. (2014) Kappa opioid receptor activation potentiates the cocaine-induced increase in evoked dopamine release recorded in vivo in the mouse nucleus accumbens. Neuropsychopharmacol. Off. Publ. Am. Coll. Neuropsychopharmacol., 39, 3036-3048.

España, R.A., Melchior, J.R., Roberts, D.C.S., \& Jones, S.R. (2011) Hypocretin 1/orexin A in the ventral tegmental area enhances dopamine responses to cocaine and promotes cocaine self-administration. Psychopharmacology, 214, 415-426.

Figlewicz, D.P., Evans, S.B., Murphy, J., Hoen, M., \& Baskin, D.G. (2003) Expression of receptors for insulin and leptin in the ventral tegmental area/ substantia nigra (VTA/SN) of the rat. Brain Res., 964, 107-115.

Figlewicz, D.P., MacDonald Naleid, A., \& Sipols, A.J. (2007) Modulation of food reward by adiposity signals. Physiol. Behav., 91, 473-478. 
Figlewicz, D.P., Bennett, J.L., Aliakbari, S., Zavosh, A., \& Sipols, A.J. (2008) Insulin acts at different CNS sites to decrease acute sucrose intake and sucrose self-administration in rats. Am. J. Physiol. Regul. Integr. Comp. Physiol., 295, R388-R394.

Floresco, S.B., West, A.R., Ash, B., Moore, H., \& Grace, A.A. (2003) Afferent modulation of dopamine neuron firing differentially regulates tonic and phasic dopamine transmission. Nat. Neurosci., 6, 968-973.

Fortin, S.M., \& Roitman, M.F. (2017a) Physiological state tunes mesolimbic signaling: Lessons from sodium appetite and inspiration from Randall R. Sakai. Physiol. Behav., 178, 21-27.

Fortin, S.M., \& Roitman, M.F. (2017b) Central GLP-1 receptor activation modulates cocaine-evoked phasic dopamine signaling in the nucleus accumbens core. Physiol. Behav., 176, 17-25.

Fulton, S., Pissios, P., Manchon, R.P., Stiles, L., Frank, L., Pothos, E.N., Maratos-Flier, E., \& Flier, J.S. (2006) Leptin regulation of the mesoaccumbens dopamine pathway. Neuron, 51, 811-822.

Göke, R., Larsen, P.J., Mikkelsen, J.D., \& Sheikh, S.P. (1995) Distribution of GLP-1 binding sites in the rat brain: Evidence that exendin-4 is a ligand of brain GLP-1 binding sites. Eur. J. Neurosci., 7, 2294-2300.

Guthoff, M., Grichisch, Y., Canova, C., Tschritter, O., Veit, R., Hallschmid, M., Häring, H.-U., Preissl, H. et al. (2010) Insulin modulates food-related activity in the central nervous system. J. Clin. Endocrinol. Metab., 95, 748-755.

Hamidovic, A., Khafaja, M., Brandon, V., Anderson, J., Ray, G., Allan, A.M., \& Burge, M.R. (2017) Reduction of smoking urges with intranasal insulin: A randomized, crossover, placebo-controlled clinical trial. Mol. Psychiatry, 22, 1413-1421.

Hanson, L. R., Fine, J. M., Svitak, A. L., \& Faltesek, K. A. (2013) Intranasal administration of CNS therapeutics to awake mice. J. Vis. Exp., 74, 4440

Havrankova, J., Schmechel, D., Roth, J., \& Brownstein, M. (1978) Identification of insulin in rat brain. Proc. Natl. Acad.sci. USA, 75, 57375741

Heni, M., Kullmann, S., Ahlqvist, E., Wagner, R., Machicao, F., Staiger, H., Häring, H.-U., Almgren, P. et al. (2016) Interaction between the obesityrisk gene FTO and the dopamine D2 receptor gene ANKK1/TaqIA on insulin sensitivity. Diabetologia, 59, 2622-2631.

Heni, M., Wagner, R., Kullmann, S., Gancheva, S., Roden, M., Peter, A., Stefan, N., Preissl, H. et al. (2017) Hypothalamic and striatal insulin action suppresses endogenous glucose production and may stimulate glucose uptake during hyperinsulinemia in lean but not in overweight men. Diabetes, 66, 1797-1806.

Hommel, J.D., Trinko, R., Sears, R.M., Georgescu, D., Liu, Z.-W., Gao, X.-B., Thurmon, J.J., Marinelli, M. et al. (2006) Leptin receptor signaling in midbrain dopamine neurons regulates feeding. Neuron, 51, 801-810.

Könner, A.C., Hess, S., Tovar, S., Mesaros, A., Sánchez-Lasheras, C., Evers, N., Verhagen, L.A.W., Brönneke, H.S. et al. (2011) Role for insulin signaling in catecholaminergic neurons in control of energy homeostasis. Cell Metab., 13, 720-728.

Kullmann, S., Frank, S., Heni, M., Ketterer, C., Veit, R., Häring, H.-U., Fritsche, A., \& Preissl, H. (2013) Intranasal insulin modulates intrinsic reward and prefrontal circuitry of the human brain in lean women. $\mathrm{Neu}$ roendocrinology, 97, 176-182.

Labouèbe, G., Liu, S., Dias, C., Zou, H., Wong, J.C.Y., Karunakaran, S., Clee, S.M., Phillips, A.G. et al. (2013) Insulin induces long-term depression of ventral tegmental area dopamine neurons via endocannabinoids. Nat. Neurosci., 16, 300-308.

Leshan, R.L., Opland, D.M., Louis, G.W., Leinninger, G.M., Patterson, C.M., Rhodes, C.J., Münzberg, H., \& Myers, M.G. (2010) Ventral tegmental area leptin receptor neurons specifically project to and regulate cocaine- and amphetamine-regulated transcript neurons of the extended central amygdala. J. Neurosci. Off. J. Soc. Neurosci., 30, 5713-5723.

Liu, S., \& Borgland, S.L. (2015) Regulation of the mesolimbic dopamine circuit by feeding peptides. Neuroscience, 289, 19-42.

Liu, S., Labouèbe, G., Karunakaran, S., Clee, S.M., \& Borgland, S.L. (2013) Effect of insulin on excitatory synaptic transmission onto dopamine neurons of the ventral tegmental area in a mouse model of hyperinsulinemia. Nutr. Diabetes, 3, e97.

Liu, S., Globa, A.K., Mills, F., Naef, L., Qiao, M., Bamji, S.X., \& Borgland, S.L. (2016) Consumption of palatable food primes food approach behavior by rapidly increasing synaptic density in the VTA. Proc. Natl. Acad.sci. USA, 113, 2520-2525.
Marks, D.R., Tucker, K., Cavallin, M.A., Mast, T.G., \& Fadool, D.A. (2009) Awake intranasal insulin delivery modifies protein complexes and alters memory, anxiety, and olfactory behaviors. J. Neurosci. Off. J. Soc. Neurosci., 29, 6734-6751.

Mebel, D.M., Wong, J.C.Y., Dong, Y.J., \& Borgland, S.L. (2012) Insulin in the ventral tegmental area reduces hedonic feeding and suppresses dopamine concentration via increased reuptake. Eur. J. Neurosci., 36, 2336-2346.

Merchenthaler, I., Lane, M., \& Shughrue, P. (1999) Distribution of pre-proglucagon and glucagon-like peptide-1 receptor messenger RNAs in the rat central nervous system. J. Comp. Neurol., 403, 261-280.

Naef, L., Pitman, K.A., \& Borgland, S.L. (2015) Mesolimbic dopamine and its neuromodulators in obesity and binge eating. CNS Spectr., 20, 574-583.

Owens, W.A., Sevak, R.J., Galici, R., Chang, X., Javors, M.A., Galli, A. France, C.P., \& Daws, L.C. (2005) Deficits in dopamine clearance and locomotion in hypoinsulinemic rats unmask novel modulation of dopamine transporters by amphetamine. J. Neurochem., 94, 1402-1410.

Patterson, T.A., Brot, M.D., Zavosh, A., Schenk, J.O., Szot, P., \& Figlewicz, D.P. (1998) Food deprivation decreases mRNA and activity of the rat dopamine transporter. Neuroendocrinology, 68, 11-20.

Paxinos, G., \& Watson, C. (2007) The Rat Brain in Stereotaxic Coordinates. 6th Edn. Amsterdam, Boston: Academic Press, Elsevier.

Sandhu, E.C., Fernando, A.B.P., Irvine, E.E., Tossell, K., Kokkinou, M., Glegola, J., Smith, M.A., Howes, O.D. et al. (2018) Phasic stimulation of midbrain dopamine neuron activity reduces salt consumption. eNeuro, $\mathbf{5}$, ENEURO.0064-18.201.

Schäffer, L., Brand, C.L., Hansen, B.F., Ribel, U., Shaw, A.C., Slaaby, R., \& Sturis, J. (2008) A novel high-affinity peptide antagonist to the insulin receptor. Biochem. Biophys. Res. Commun., 376, 380-383.

Schoffelmeer, A.N.M., Drukarch, B., De Vries, T.J., Hogenboom, F., Schetters, D., \& Pattij, T. (2011) Insulin modulates cocaine-sensitive monoamine transporter function and impulsive behavior. J. Neurosci. Off. J. Soc. Neurosci., 31, 1284-1291.

Sevak, R.J., Koek, W., Owens, W.A., Galli, A., Daws, L.C., \& France, C.P. (2008) Feeding conditions differentially affect the neurochemical and behavioral effects of dopaminergic drugs in male rats. Eur. J. Pharmacol., 592, 109-115.

Speed, N., Saunders, C., Davis, A.R., Owens, W.A., Matthies, H.J.G., Saadat, S., Kennedy, J.P., Vaughan, R.A. et al. (2011) Impaired striatal Akt signaling disrupts dopamine homeostasis and increases feeding. PLoS One, 6, e25169.

Stouffer, M.A., Woods, C.A., Patel, J.C., Lee, C.R., Witkovsky, P., Bao, L., Machold, R.P., Jones, K.T. et al. (2015) Insulin enhances striatal dopamine release by activating cholinergic interneurons and thereby signals reward. Nat. Commun., 6, 8543.

Strubbe, J.H., Porte, D., \& Woods, S.C. (1988) Insulin responses and glucose levels in plasma and cerebrospinal fluid during fasting and refeeding in the rat. Physiol. Behav., 44, 205-208.

Thompson, J.L., \& Borgland, S.L. (2013) Presynaptic leptin action suppresses excitatory synaptic transmission onto ventral tegmental area dopamine neurons. Biol. Psychiatry, 73, 860-868.

Vigneri, R., Squatrito, S., \& Sciacca, L. (2010) Insulin and its analogs: Actions via insulin and IGF receptors. Acta Diabetol., 47, 271-278.

Wanat, M.J., Willuhn, I., Clark, J.J., \& Phillips, P.E.M. (2009) Phasic dopamine release in appetitive behaviors and drug addiction. Curr. Drug Abuse Rev., 2, 195-213.

Wang, X.-F., Liu, J.-J., Xia, J., Liu, J., Mirabella, V., \& Pang, Z.P. (2015) Endogenous glucagon-like peptide-1 suppresses high-fat food intake by reducing synaptic drive onto mesolimbic dopamine neurons. Cell Rep., 12 726-733.

Williams, J.M., Owens, W.A., Turner, G.H., Saunders, C., Dipace, C., Blakely, R.D., France, C.P., Gore, J.C. et al. (2007) Hypoinsulinemia regulates amphetamine-induced reverse transport of dopamine. PLoS Biol., 5, e274.

Wilson, C., Nomikos, G.G., Collu, M., \& Fibiger, H.C. (1995) Dopaminergic correlates of motivated behavior: Importance of drive. J. Neurosci., 15, 5169-5178.

Zweifel, L.S., Argilli, E., Bonci, A., \& Palmiter, R.D. (2008) Role of NMDA receptors in dopamine neurons for plasticity and addictive behaviors. $\mathrm{Neu}$ ron, 59, 486-496.

Zweifel, L.S., Parker, J.G., Lobb, C.J., Rainwater, A., Wall, V.Z., Fadok, J.P., Darvas, M., Kim, M.J. et al. (2009) Disruption of NMDAR-dependent burst firing by dopamine neurons provides selective assessment of phasic dopamine-dependent behavior. Proc. Natl. Acad.sci. USA, 106, $7281-7288$. 